\title{
Population dynamics and habitat preferences of Phlebotomus orientalis in extra-domestic habitats of Kafta Humera lowlands - kala azar endemic areas in Northwest Ethiopia
}

Wossenseged Lemma ${ }^{1,2^{*}}$, Habte Tekie ${ }^{2}$, Meshesha Balkew ${ }^{3}$, Teshome Gebre-Michael ${ }^{3}$, Alon Warburg ${ }^{4}$ and Asrat Hailu ${ }^{5}$

\begin{abstract}
Background: Kafta Humera lowlands are endemic for kala-azar (visceral leishmaniasis). These lowlands are characterized by black clay soil which is used for growing sesame, sorghum and cotton for commercial purposes.

The aim of this study was to determine seasonal dynamics and habitat preferences of Phlebotomus orientalis, the vector of kala-azar, in extra-domestic habitats of Kafta Humera lowlands.

Methods: CDC-light Trap [CDC-LT] and Sticky paper Trap [ST] were used to collect sand flies from different habitats before species identification by their morphological characteristics using appropriate keys. Data summarized and analyzed included: species, sex, density, habitats, type of trap used and date (month).

Results: A total of 389,207 sand flies using CDC-LT ( $n=955)$ and ST $(n=5551)$ were collected from May 17, 2011 to June 6, 2012. The highest Mean Monthly Density (MMD) of P. orientalis trapped by CDC-LT was found in thickets of Acacia seyal in March (64.11 \pm 75.87$)$. The corresponding highest MMD of $P$. orientalis trapped by STs was found in April (58.69 \pm 85.20$)$ in agricultural field. No $P$. orientalis were caught in September using CDC traps and July-October using sticky traps. The overall MMD of $P$. orientalis trapped by CDC-LT was $15.78 \pm 28.93(n=320)$ in agricultural field, $19.37 \pm 36.42(n=255)$ in thickets of $A$. seyal, and $3.81 \pm 6.45(n=380)$ in dense mixed forest. Similar habitats in different localities did not show statistically significant difference for the MMD of $P$. orientalis trapped by CDC-LT $(p=0.117)$ and ST ( $p=0.134)$.
\end{abstract}

Conclusion: Agricultural fields and thickets of $A$. seyal habitats, which exhibit extensive soil cracks and fissures, as opposed to dense mixed forests, serve as preferred breeding sites for $P$. orientalis.

Keywords: Population dynamics, Habitat preferences, P. orientalis, Extra-domestic habitats, Kafta Humera lowlands, Kala-azar

\section{Background}

Visceral leishmaniasis (VL) or kala-azar is vector borne disease that is almost fatal if left untreated [1,2]. More than $90 \%$ of VL cases in the world occur in Bangladesh, India, Nepal, Sudan, Ethiopia and Brazil [2]. Phlebotomus martini and Phlebotomus orientalis are the two principal

\footnotetext{
* Correspondence: wossensegedlemma@yahoo.com

'Department of Parasitology, School of Biomedical and Laboratory Sciences, College of Medicine and Health Sciences, University of Gondar, P.O. box: 196, Gondar, Ethiopia

${ }^{2}$ Department of Zoology, Faculty of Life Science, Addis Ababa University, Addis Ababa, Ethiopia

Full list of author information is available at the end of the article
}

vectors of kala-azar in East Africa [3,4]. Phlebotomus martini is associated with Macrotermes termite mounds in southern Ethiopia [5] while P. orientalis is associated with Acacia seyal - Balanites aegyptiaca forest and deeply cracking soil in eastern Sudan and northwestern Ethiopia [6-18]. P.orientalis is believed to depend on the black cracking soil as day resting and breeding site in dry season $[7,8]$. Elnaiem et al. [14] considered termite mound as principal day resting site for $P$. orientalis compared to tree holes, crevices, soil cracks and chicken coops in eastern Sudan. The breeding site of $P$. orientalis has not been identified beyond doubt as attempts to find larvae were not successful [7].

\section{Biomed Central}

(C) 2014 Lemma et al.; licensee BioMed Central Ltd. This is an Open Access article distributed under the terms of the Creative Commons Attribution License (http://creativecommons.org/licenses/by/4.0), which permits unrestricted use, distribution, and reproduction in any medium, provided the original work is properly credited. The Creative Commons Public Domain Dedication waiver (http://creativecommons.org/publicdomain/zero/1.0/) applies to the data made available in this article, unless otherwise stated. 
Further, the sugar feeding habits and diapauses of this species have not been described [7,8]. The reservoir hosts of zoonotic VL (ZVL) in Eastern Africa Region are not known. Due to lack of knowledge on zoonotic transmission cycles and the ecology of the vector, little has been achieved in control of VL in the region. A. seyal - B. aegyptiaca forest was reported to have the highest $P$. orientalis population in Sudan [7,12,13,15-17]. Elnaiem et al., [16] described $P$. orientalis as forest species with special preference to dense A. seyal than B. aegyptiaca, Combretum kordofanum, Hyphaena or Zizipus trees. The smooth surface of A. seyal, however, lacks cracks, fissures or cavities to serve as resting site during wet rainy season as oppose to Balanites sp. or other trees in the forest [7].

Metema-Humera lowlands in northwest Ethiopia are endemic for kala-azar and accounted $60 \%$ of all VL cases in Ethiopia [1]. Matema-Humera lowlands are, geographically, an extension of eastern Sudan $[8,15,17]$ and have similar rainfall pattern and vegetation $[7,8]$. The most kala-azar affected part of Matema-Humera lowlands is the Kafta-Humera district with the annual incidence that range from 1000 to 2000 cases, with higher prevalence $(>80 \%)$ in labour migrants from Amhara and Tigray highland areas compared to the permanent residents in the area [19]. World Health organization report on leishmaniasis in tropical Africa [20] indicated that $45.6 \%$ of Humera population involved in farm activities were positive for leishmanin skin test compared to $8.3 \%$ in non-farmers (urban and farm-owning population) with annual sero-conversion rate of $7 \%$ and less than $1 \%$ respectively. Kala azar infections in labour migrants from non-endemic highland areas of Tigray and Amhara regions were addressed to the travel history to Kafta-Humera [21,22]. Almost all $(156 / 157$ or $99.4 \%)$ kala azar cases in the labour migrant visiting Kafta Humera during June - October rainy season were aged from 15 to 49 compared to $68.9 \%$ (104/ 151) in permanent residents for the same age group (22) indicating this age group, that involved in agricultural activities in the extra-domestic habitats, as high risk group. Kala azar is the most important public health problem and cause high mortality and morbidity rate, especially among the young adult working forces, and has serious impact on the socio-economy of Kafta-Humera district. While treatment of kala-azar patients saves lives, it does not stop the disease from becoming a public health threat. Prevention of kala-azar transmission by vector control requires in depth understanding of the biology and ecology of sand fly vectors. Study on population dynamics and habitat preferences of $P$. orientalis are among the first steps in vector management to control kala-azar. Thus, the aim of this study was to describe the seasonal dynamics of $P$. orientalis and habitat preferences in extra-domestic habitats of the Kafta Humera lowlands.

\section{Methods}

\section{Study area}

Kafta Humera district (wereda) is found in Western Tigray Zone which includes Welkait and Tsegede districts (Figure 1). Humera town is the administrative center of the district. It has latitude $14^{\circ} 17^{\prime} \mathrm{N}$ and longitude $036^{\circ} 39^{\prime} \mathrm{E}$ at an altitude of $637 \mathrm{~m}$ above sea level. Repatriation of 14, 255 refugees from Saffawa and Umrakoba camps in eastern Sudan in 1993 and 1994 around Humera, resulted in an emergence of Rawyan $\left(14^{\circ} 17^{\prime} 19^{\prime \prime} \mathrm{N}, 036^{\circ} 37^{\prime}\right.$ $18^{\prime \prime} \mathrm{E}, 600 \mathrm{~m}$ a.s.l), May Kadra (140' $\mathrm{N}, 036^{\circ} 34^{\prime} \mathrm{E}, 612 \mathrm{~m}$ a.s.l), and Adebay (14 $17^{\prime} 22^{\prime \prime} \mathrm{N}, 036^{\circ} 38^{\prime} \mathrm{E}, 625 \mathrm{~m}$ a.s.l) towns. These settlements were after the end of the war in 1980's and the Ethiopian People Democratic Front (EPDF) came to power. Before the settlements, about 720 people were living in May Kadra. The other town around Humera is Baeker which was a small village before Ethio-Eritrea war which displaced people from border areas around Humera and forced them to settle in Beaker. Epidemic of kala azar was erupted in 1995 [1], particularly in May Kadra (including Berket settlement center), which might be related to the movement of immunologically naïve people into kala azar endemic areas. Adebay is located $25 \mathrm{~km}$ away from Humera to eastern direction. May Kadra is a town located $25 \mathrm{~km}$ South of Humera. Rawyan is found between May Kadra and Humera. Baeker is located east of May Kadra at $40 \mathrm{~km}$ or southeast of Humera, at $53 \mathrm{~km}$ (Figure 1). Further east, towards Welkait district, at around $45 \mathrm{~km}$ from Baeker, is the Kafta town. Except the areas around Kafta town (above $1000 \mathrm{~m}$ a.s.l), all the lowlands (around $600 \mathrm{~m}$ a.s.l) in Kafta Humera district are endemic for kala azar. The district has a total population of 92,167(47,909 men and 44,258 women) and covers an area of 4,542.33 square $\mathrm{km}$ [23]. In Kafta Humera lowlands, the towns are surrounded by uniform agricultural fields that occasionally interrupted by thickets of $A$. seyal in depressions. All the dense mixed forests were converted into agricultural fields except in the part of Kafta Shiraro Park and some rocky outcrops.

\section{Study sites and habitats}

A preliminary survey was conducted during field trip in May $15-28,2010$ to identify the habitats in the study area by the research team from Addis Ababa and Hebrew Universities. Sand fly sampling sites were selected from extra-domestic habitats areas around the Adebay (Site-1), Baeker (Site 2), and May Kadra (Site 4) towns where labour migrants perform agricultural activities during wet rainy season (Figure 2). The sampling sites were at least $10 \mathrm{~km}$ away from these towns. Site 4 was located $23 \mathrm{~km}$ south of the May Kadra in an area called Gelanzeraf closer to the Sudan boarder $\left(13^{\circ} 59^{\prime} \mathrm{N}\right.$ and $\left.036^{\circ} 31^{\prime} \mathrm{E}\right)$. Each site had agricultural field, thicket(s) of $A$. seyal and dense mixed forest habitats (Figure 2) for sand fly sampling 


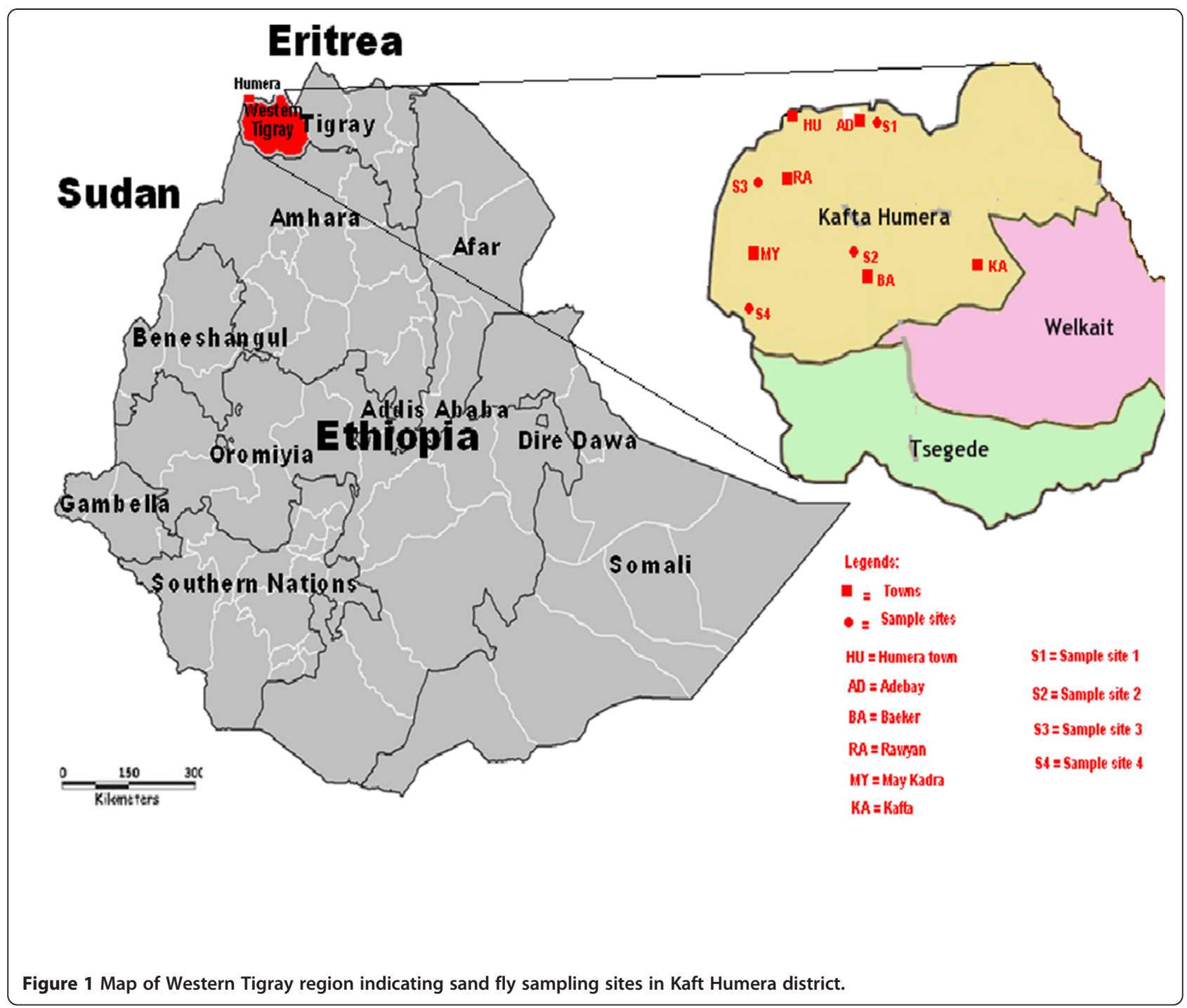

except Adebay and Rawyan where thicket of $A$. seyal and dense mixed forest were missing respectively. The shortest possible distance between two sampling sites (site 1 - site 3) was $35 \mathrm{~km}$ compared to $60 \mathrm{~km}$ longest distance (site 1site 4). The agricultural fields that were used as sample sites were those which have been used for cultivation of sesame. All the thickets of $A$. seyal sample sites were found in depression where water floods during rainy season, next to agricultural fields. The thickets of $A$. seyal in around Rawyian town were dense ( $>20$ trees $/ 100 \mathrm{~m}^{2}$ ) compared to the sparse $\left(10-20\right.$ trees $\left./ 100 \mathrm{~m}^{2}\right)$ in around the Baeker town or both thin (5-10 trees/100 $\mathrm{m}^{2}$ ) and sparse in Gelanzeraf area. The two ends of dense mixed forest ( $>20$ trees/ $100 \mathrm{~m}^{2}$ ) extending between Adebay and Beaker towns (about $45 \mathrm{~km}$ ) were used as extra-domestic sampling sites around Adebay (site 1) and Baeker (site 2). This forest is part of the Kafta Shiraro National Park - the largest park in
Ethiopia. Another dense mixed forest with rocky and black soil was also used as sample site in Gelanzeraf area. The Common trees and shrubs in Kafta Humera areas are $A$. seyal, A. mellifera, B. aegyptiaca, Terminalia spp., Boswellia papyrifera, Ficus sycomorus, Sclerocarya birrea, Zizypus spp., Dalbergia melanoxylon, Boscia angustifolia, Sterculia Africana, Adansonia digitata, Dichrostachys cineria and Syzgium guineese. The field study and sand fly collection were conducted from May 17, 2011 to June 6, 2012.

\section{Climate}

Information about mean average annual rainfall, mean maximum and minimum temperature of Humera and Baeker towns during January 2011 to December 2013 were obtained from Ethiopian National Meteorology agency to describe the climate of the study area. 


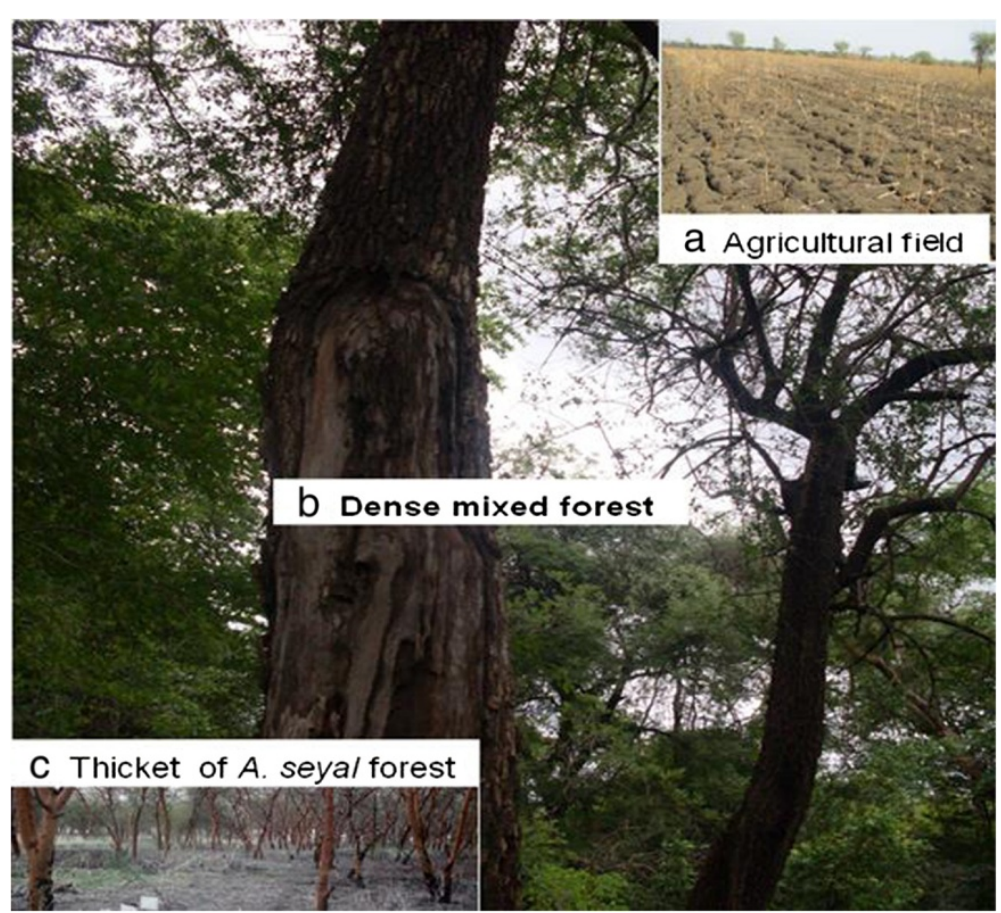

Figure 2 Agricultural field (a), dense mixed forest (b) and thickets of Acacia seyal forest (c) habitats from where sand flies were sampled.

\section{Sand flies collection and identification}

At least 12 CDC - light traps/month (Model512, Hock and Co.,USA) were used to collect sand flies from agricultural fields, thickets of $A$. seyal and dense mixed forests at the four localities (sampling sites). Similarly, $20-388$ sticky traps/month were used to collect sand flies from the three habitats. CDC light traps were set at 6 p.m, hanged at about 0.5 meter above ground level, and left overnight till 6 a.m. Sesame oiled sticky traps were randomly placed horizontally on the ground at about $5 \mathrm{~m}$ interval. Sand flies from sticky traps were collected in 95\% alcohol before transferring to saline containing detergent for washing, sorting and counting Sergentomyia and Phlebotomus spp. Similarly, sand flies collected using CDC traps were sorted and counted. Sand flies were dissected in saline and mounted in Hoyer's medium, after the head is separated and turned upside down before placing cover slip. The last segment of the abdomen was also removed for visualizing the spermathecae in female sand flies. Species identification was carried out using the appropriate keys $[7,24,25]$.

\section{Study on habitat preference and population dynamics (Bionomics)}

The sand fly species, sex, habitat, numbers, date and type of trap used were documented. Mean Monthly Density (MMD) of trapped sand flies was determined by total counts divided by number of traps used. Comparisons of $P$. orientalis MMD in different habitats were used for study of habitat preference of this vector. Similarly, MMD of $P$. orientalis at different months were used to determine the population dynamics. Resting sites of $P$. orientalis in the dense mixed forest during rainy season were determined by comparing the result of $P$. orientalis cached using the sticky traps placed on the ground and the emergence traps deployed on the tree trunks. Hand used torch light battery was also used for making observations of sand flies resting sites.

\section{Statistical analysis}

The density of sand flies calculated as average numbers of male and female sand flies per trap per day and the results were entered into Statistical Package of Social Sciences (SPSS) version 16 for analysis of the data using descriptive statistics (Mean $\pm \mathrm{SD}$ ), analysis of variance (ANOVA) and Post hoc Tukey Honestly Significant Difference (HSD) tests so that seasonal dynamics and habitat preferences of $P$. orientalis could be studied. P-values less than 0.05 were considered as statistically significant difference.

\section{Results}

Climate: temperature and rainfall

The annual mean maximum temperature varied from 29.10 to $41.2^{\circ} \mathrm{C}$ while the monthly mean minimum from 13.50 to $25.40^{\circ} \mathrm{C}$ in Baeker and Humera towns (Figure 3). November to May was dry season and characterized by high mean maximum temperature $\left(35.7-40.83^{\circ} \mathrm{C}\right)$, lack of heavy rain and cracking of black soil. Wet rainy season 


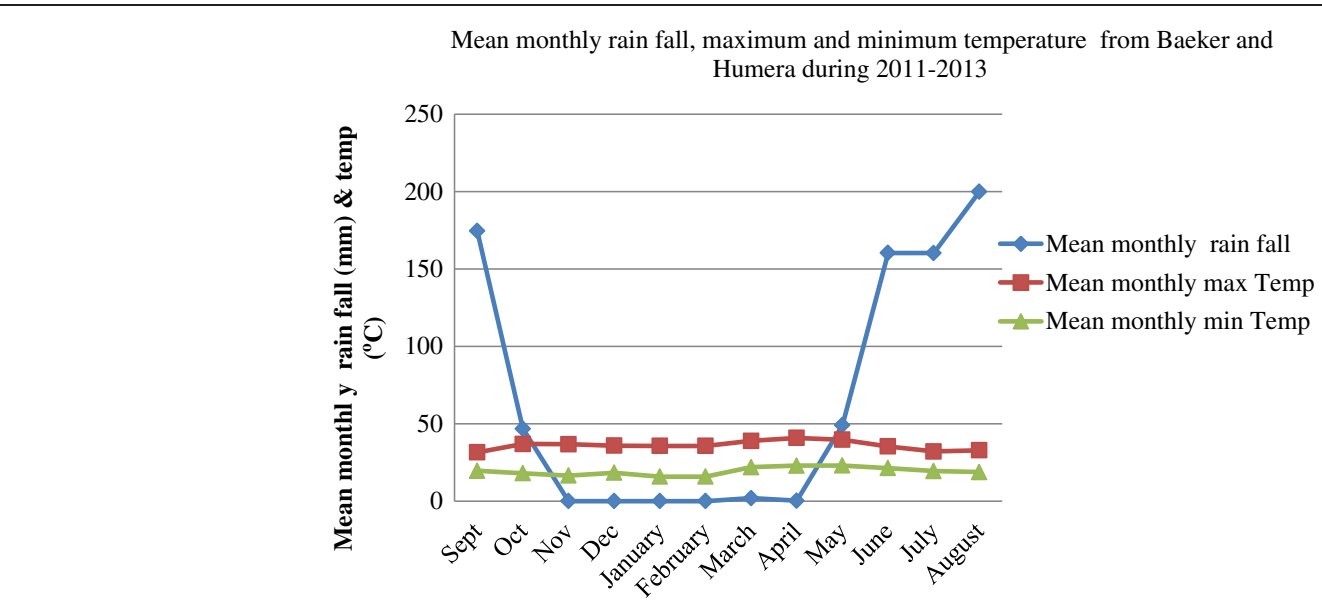

Figure 3 Mean maximum $\left({ }^{\circ} \mathrm{C}\right)$, Mean Minimum temperature $\left({ }^{\circ} \mathrm{C}\right)$, and rain fall $(\mathrm{mm})$ of Humera and Baeker towns from January 2011 to December 2013.

was found during June - October. The heaviest rain occurred in August (199.97 mm). The binging of rain was in May $(49.08 \mathrm{~mm})$, although this month remained very hot $\left(39.66^{\circ} \mathrm{C}\right)$. The Average annual rainfall received by the area from January 2011 to December 2013 was $791 \mathrm{~mm}$. March - May considered as hottest season $\left(38.9-40.83^{\circ} \mathrm{C}\right)$ compared to October - February $(35.7$ $\left.36.88^{\circ} \mathrm{C}\right)$ and June - September rain season $\left(31.5-35.33^{\circ} \mathrm{C}\right)$. Strong wind which started in the begging of rain (May) continued until it settled down in July. Strong winds affected the collection of sand flies in May and June. After the heaviest rains in August, depressions were flooded with water and rivers reached their peak height.

\section{Phlebotomus orientalis density}

A total of 376,441 sand flies were collected using CDC $(\mathrm{n}=955)$ and sticky traps $(\mathrm{n}=5551)$ from agricultural fields, thickets of $A$. seyal and dense mixed forests during the study period. Of the total sand flies collected using $\mathrm{CDC}$ and sticky traps (STs) from the three types of habitats, 62,733 (5,546 female and 57,187 male) or $16.7 \%$ were $P$. orientalis. There was statistically significant difference between mean values of $P$. orientalis/traps for different $\operatorname{sex}(\mathrm{p}=0.001)$. The Mean $\pm \mathrm{SD}$ of $P$. orientalis/CDC in all habitats was $8.03 \pm 20.77$ (range: 0-144.33) for male and $3.62 \pm 7.01$ (range: 0-49) for female. Similarly, the overall Mean \pm SD of $P$. orientalis/sticky was $9.57 \pm 27.07$ (range: $0-295$ ) for male and $0.32 \pm 0.92$ (range: $0-11$ ) for female. Almost all (99\%) Phlebotomus spp found in the extradomestic study sites were $P$. orientalis (Table 1 ).

\section{Population dynamics}

For CDC traps, the highest MMD of $P$. orientalis/CDC was found in thickets of $A$. seyal in March (64.11 \pm 75.87$)$; and lowest was found in September $(0 \pm 0)$ in agricultural field. The highest $P$. orientalis/sticky was found in April
$(58.69 \pm 85.20)$ in the agricultural field; and the lowest $(0 \pm 0)$ was found during July-October wet and rainy season in all habitats (Figure 4). When post hoc (HSD) tests were performed for mean $P$. orientalis/CDC in April, there was no significant mean difference with January $(\mathrm{p}=0.384)$, February $(\mathrm{p}=0.980)$ and March $(\mathrm{p}=$ $0.783)$ as opposed to the other months $(\mathrm{p}<0.05)$. During rainy time, MMD of $P$. orientalis/CDC sharply decreased in June and July both in agricultural field and thickets of A. seyal compared to dense mixed forest which showed a highest MMD of $P$. orientalis/CDC $(7.94 \pm 10.50)$ in July with female: male ratio of 5.47:1. Dense mixed forest yielded $13.2 \%$ of the total $P$. orientalis collected from all habitats after using $392 \mathrm{CDC}$ - traps or $39.4 \%$ of the total CDC traps used in this study. Of all $P$. orientalis (1577) collected from the dense mixed forest, 57.9\% (772 female and 141 male) were trapped in July ( 8 P. orientalis/CDC) using 104 CDC traps $(27.36 \%$ of the CDC traps used in dense mixed forest) (Figure 4).

\section{Habitat preference}

The overall MMD of $P$. orientalis (female + male) trapped by CDC-LT was $15.78 \pm 28.93(\mathrm{n}=320)$ in agricultural field, $19.57 \pm 36.42(\mathrm{n}=255)$ in thickets of $A$. seyal, and $3.81 \pm 6.45(\mathrm{n}=380)$ in dense mixed forest. For STs, the overall MMD of P. orientalis was $14.76 \pm$ $38.78(\mathrm{n}=2378)$ in agricultural field, $11.45 \pm 15.56(\mathrm{n}=$ $1500)$ in the thickets of $A$. seyal and $0.95 \pm 2.16$ ( $\mathrm{n}=$ 1168 ) in dense mixed forest. ANOVA result has showed statistically significant mean difference $(p=0.000)$ for different habitats. However, similar habitats in different localities did not show statistically significant difference for the MMD of $P$. orientalis trapped by CDC-LT $(\mathrm{p}=$ $0.117)$ and ST ( $\mathrm{p}=0.134)$. During the August rains, habitat with more protection such as dense mixed forest, harbored more number of $P$. orientalis/CDC $(1.04 \pm 1.2)$ 
Table 1 Total sand flies collected from the agricultural fields, thickets of $A$. seyal and dense mixed forest using CDC and sticky traps from May 17, 2011 to June 6, 2012 G.C

\begin{tabular}{|c|c|c|c|c|c|c|}
\hline \multirow[b]{2}{*}{ Species } & \multicolumn{3}{|c|}{ CDC (No. traps $(n)=955)$} & \multicolumn{2}{|c|}{ Sticky $(n=5551)$} & \multirow[b]{2}{*}{ Total } \\
\hline & Female & Male & Total & Female & Male & \\
\hline Phlebotomus orientalis & 3,876 & 8,512 & 12,388 & 1,670 & 48,675 & 50,345 \\
\hline P. papatasi & 88 & 189 & 277 & 16 & 224 & 240 \\
\hline P. duboscai & 7 & 24 & 31 & 0 & 0 & 0 \\
\hline P. bergeroti & 0 & 21 & 21 & 0 & 0 & 0 \\
\hline P. rodhaini & 30 & 6 & 36 & 0 & 27 & 27 \\
\hline P. martini & 0 & 10 & 10 & 0 & 0 & 0 \\
\hline P. alexandri & 0 & 11 & 11 & 0 & 0 & 0 \\
\hline Sergentomyia spp & 90,078 & 74,314 & 164,392 & 92,383 & 56,280 & 148,663 \\
\hline Total & 94,079 & 83,087 & 177,166 & 94,069 & 105,206 & 199,275 \\
\hline
\end{tabular}

compared to agricultural fields $(0.24 \pm 0.42)$ and thickets of $A$. seyal $(0.2 \pm 0.44)$. Sticky traps placed on the ground in July and August did not collect sand flies when compared to emergence traps deployed on the tree trunks in the dense mixed forests. A total of 44 (32 female, 12 male) P. orientalis and 8115 Sergentomyia sp. (3736 female, 4379 male) were collected using 77 emergence traps.

Baeker sparse thickets of $A$. seyal (counts of $29.37 \pm$ 49.41) and thin and sparse thickets in Gelanzeraf (with counts of $28.00 \pm 41.33$ ) were ranked first and second compared to the different habitats in different sites based on mean number of $P$. orientalis/CDC during the study period. The other habitats with higher mean $P$. orientalis/CDC values were agricultural fields in Baeker (counts of $22.47 \pm$ 33.24) and Adebay (counts of $21.11 \pm 34.07$ ). ANOVA for mean number $P$. orientalis/CDC between sparse thickets of A. seyal in Beaker and sparse and thin thickets of $A$. seyal in Gelanzeraf showed no statistically significant difference ( $p>0.05)$. Similarly, ANOVA for mean number P. orientalis/CDC in Adabay and Beaker agricultural fields showed no difference $(\mathrm{p}>0.05)$. The mean number $P$. orientalis/CDC in the agricultural fields of Gelanzeraf $(5.00 \pm 9.57, \mathrm{n}=81)$ was very low compared to the thickets in the same area $(28 \pm 41.33, \mathrm{n}=149)$. The mean number $P$. orientalis/CDC of dense thickets of $A$. seyal $(2.74 \pm 3.64, \mathrm{n}=78)$ of Rawyan was as low as the agricultural field $(1.57 \pm 3.09, \mathrm{n}=49)$ in the same area. Generally, dense mixed forests in all sites also have low (3.81 $\pm 6.45, \mathrm{n}=357)$ mean $P$. orientalis/CDC during the study period and showed no statistically significant mean differences $(\mathrm{p}=0.22)$ (Table 2). When mean $P$. orientalis/CDC for all thickets $(19.37 \pm 36.42, \mathrm{n}=248)$ and dense mixed forest $(3.81 \pm 6.45)$ were compared, there was statistically significant difference between these values $(\mathrm{p}=000)$. But, no difference $(\mathrm{p}=0.55)$ was observed between dense A. seyal in Rawyan (2.86 8 $3.69, \mathrm{n}=83$ ) and the dense mixed forests. Post hoc Tukey HSD test has showed sparse and thin Gelanzeraf thickets of $A$. seyal had almost the same mean number $P$. orientalis/CDC with sparse thickets of Beaker Site 2 $(\mathrm{p}=0.994)$ but different mean counts when compared to dense Rawyan thickets of A. seyal ( $\mathrm{p}=0.036)$.

\section{Discussion}

Three decades ago, the vegetations of Metema - Humera lowlands were described as $A$. seyal - B. aegyptiaca forest and Argeissus - Combretum savannah woodlands [26] which have now been converted mainly into big mechanized agricultural fields, especially in Kafta Humera district. Absence of A. seyal - B. aegyptiaca forests and termite mounds in the study areas in this district gave advantage to analyze fewer habitats such as agricultural fields and thickets of $A$. seyal in addition to dense mixed forests in the periphery of Kafta - Shiraro National Park. These habitats are distinctly separated from each other as opposed to habitats studied previously that had no demarcation between agricultural fields and the different types of forests $[7,14,16]$.

In the highlands of Belessa valley in Ethiopia, the population of $P$. orientalis was reported to show no significant variation from September (rainy season) to April (dry season) [27]. In contrast, in Sudan, the numbers of P. orientalis captured using STs were reported to be few in the early dry season (January and February) and increased significantly in March until it reached peak number in April. The population of $P$. orientalis declined in May and June when rain commenced $[7,8]$. Similarity in the result between numbers of $P$. orientalis/trap in Sudan and this study could be due to similar ecology shared between eastern Sudan and northwestern Ethiopia along the border areas $[8,16]$. During the study of sand flies in the Dinder National Park next to Ethiopian border, P. orientalis showed a slight peak from December 1994 to February 1995 and then dropped in March - May, and then peaked suddenly in June 1995 in thickets of $A$. seyal [14]. In this study, however, $P$. orientalis was reached peak mean numbers in March and April with sudden dropped in May 


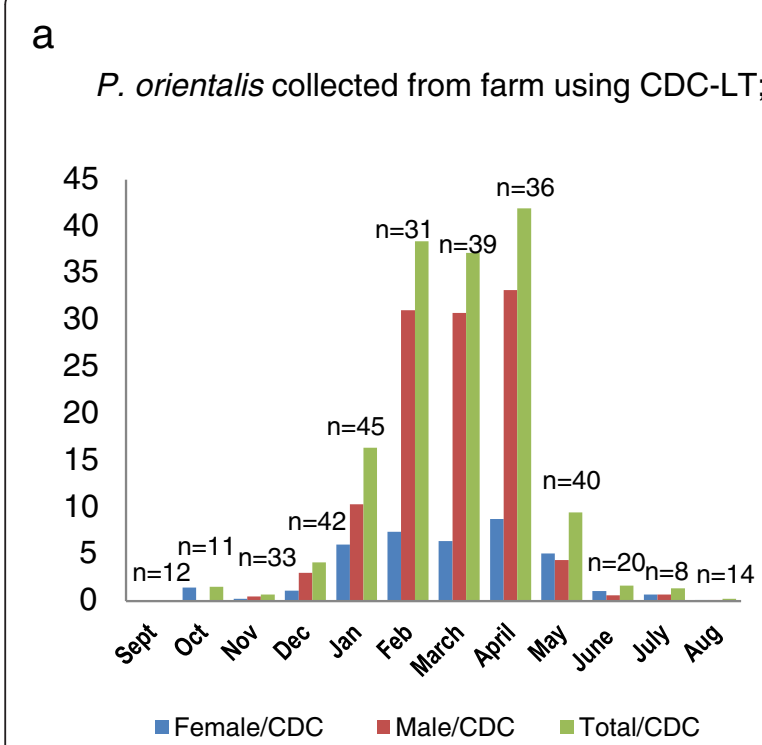

C

$P$. orientalis CDC-LT collection from thicket of $A$. seyal;

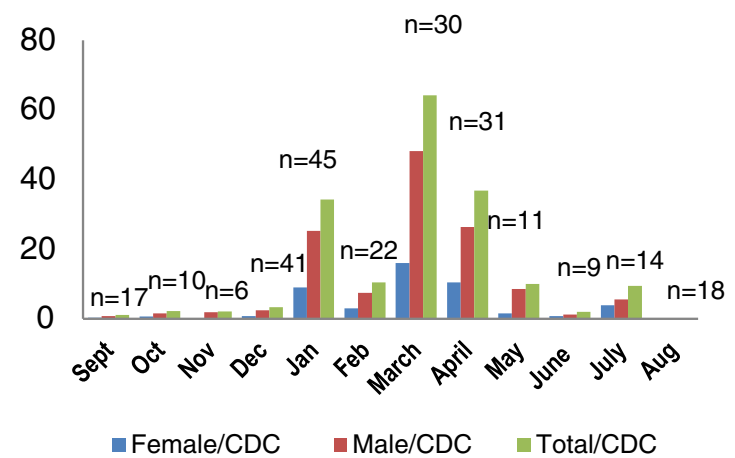

e

P. orientalis collected from dense mixed forest usingCDC-LT;

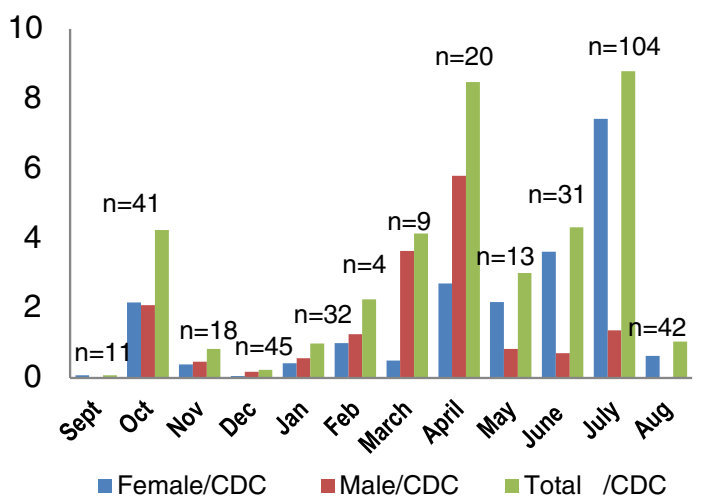

b

$P$. orientalis collected from agricultural fields using STs.

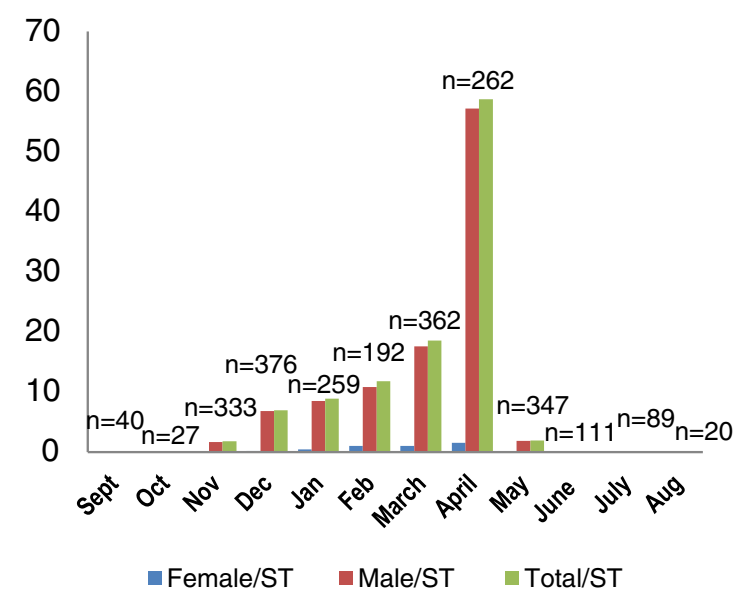

d

P. orientalis STs collection from thickets of $A$. seyal.

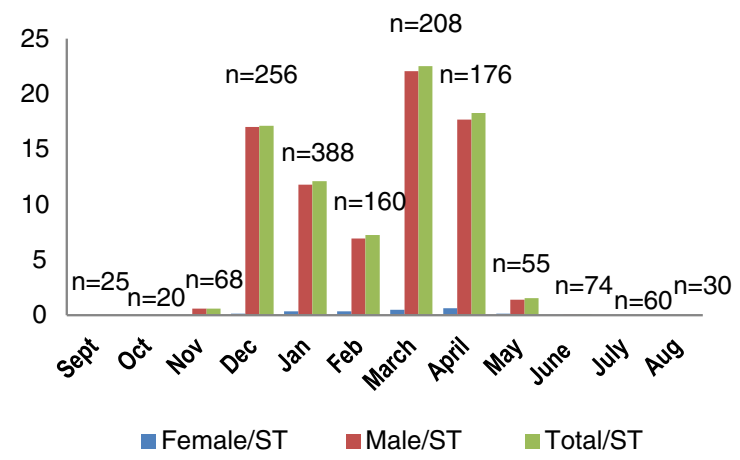

$f$

P. orientalis colleted from dense mixed forest using STs.

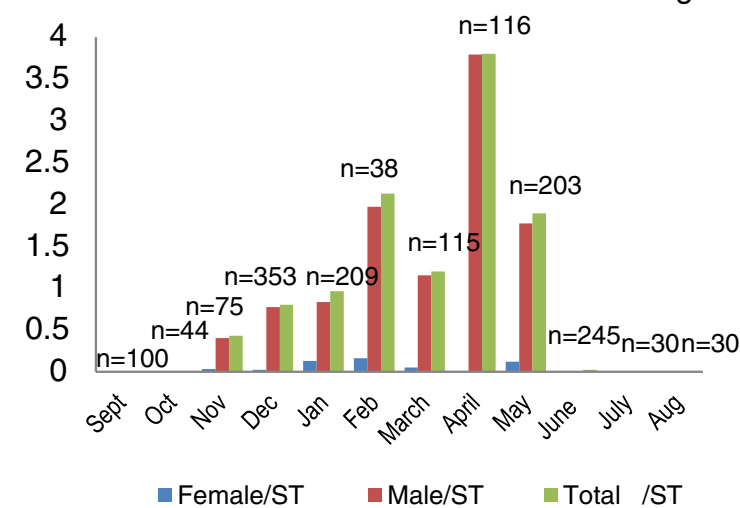

Figure 4 Mean P. orientalis/trap in farm (a-b), thickets of A. seyal (c-d) and dense forest (e- f) habitats from May 2011 to June 2012. $n=$ no. traps used for each month.

(Figure 4). The effect of wind in affecting sand fly collection in May and June should not be under estimated. The trend of seasonal dynamics of $P$. orientalis in dense mixed forest did not fully match the patterns in agricultural field and thickets of $A$. seyal (Figure 4). Generally, MMD in dense mixed forest was low compared to other habitats, 
Table 2 P. orientalis abundance in different sampling sites in relation to specific habitats, i.e., agricultural fields, thickets of $A$. seyal and mixed forest using CDC traps

\begin{tabular}{|c|c|c|c|c|c|c|c|c|c|}
\hline \multirow[t]{3}{*}{ Locality } & \multicolumn{3}{|c|}{ Agricultural field } & \multicolumn{3}{|c|}{ Thickets of $A$. seyal } & \multicolumn{3}{|c|}{ Dense mixed forest } \\
\hline & \multicolumn{3}{|c|}{ P. orientalis/CDC } & \multicolumn{3}{|c|}{ P. orientalis/CDC } & \multicolumn{3}{|c|}{ P. orientalis/CDC } \\
\hline & $\mathrm{CDC}$ & Mean & Std.D & $\mathrm{CDC}$ & Mean & Std.D & $\mathrm{CDC}$ & Mean & Std.D \\
\hline Adebay extra domestic site 1 & 110 & 25.99 & 36.98 & - & - & - & 92 & 4.75 & 6.03 \\
\hline Baeker extra domestic site 2 & 78 & 22.47 & 33.24 & 31 & 29.37 & 49.41 & 149 & 4.60 & 8.14 \\
\hline Gelanzeraf extra domestic site 4 & 85 & 5.00 & 9.57 & 140 & 28.00 & 41.33 & 116 & 1.41 & 2.09 \\
\hline Rawyan extra domestic site 3 & 47 & 1.57 & 3.09 & 77 & 2.74 & 3.64 & & & \\
\hline Total & 320 & 15.78 & 28.93 & 255 & 19.37 & 36.42 & 380 & 3.81 & 6.45 \\
\hline
\end{tabular}

but it showed an increase during dry season as other habitats until July. In July, MMD reached its peak value unlike other habitats where $P$. orientalis population declined. These results might be enough for the conclusion of dense mixed forest not to be the breeding site for $P$. orientalis. The seasonal changes in $P$. orientalis population in dense mixed forest might be due to the inter-habitat shift of this vector. During rain and wind stress season (May-June), $P$. orientalis from neighboring agricultural fields and thickets of $A$. seyal might have shifted to dense mixed forests where cracks and burrows in tree trunks serve them protected. The cooler temperature inside the forest, which has prevented soil crack formation, might have played a significant role for dense forests not to act as breeding site.

Due to the fact that most previous studies $[7,8,14]$ have considered $P$. orientalis as forest species and owing to the lack of comparisons among different types of forests (thickets of $A$. seyal, A. seyal - B. aegyptiaca and dense mixed forests), the exact habitats of $P$. orientalis were not identified. The overall mean collections of $P$. orientalis using sticky traps from the three different habitats such as 11.50 /sticky traps $(n=2418)$ from agriculture fields, 12.17 / sticky ( $\mathrm{n}=1500)$ from thickets of $A$. seyal and $1.08 /$ sticky $(\mathrm{n}=1633)$ from dense mixed forest in Kafta-Humera lowlands could be compared with similar study in Sudan [7]. The overall result of mean $P$. orientalis/sticky from the different forests in the Paloich areas in South Sudan 0.195/ sticky trap $(n=100)$ [7] was similar with the result obtained from dense mixed forest in Kafta Humera districts. These results were lower than the overall results obtained from agricultural fields and thickets of $A$. seyal and might also suggest dense forests not to be breeding sites for $P$. orientalis. Habitats with cracks during dry season due to exposure to the heat of the sun such as agricultural fields and less dense thickets of $A$. seyal might be a breeding sites of $P$. orientalis. Males of $P$. orientalis collected from thickets of $A$. seyal and agricultural fields were found with unrotated genitalia (data not shown) indicating these habitats as places where this vector emerged from larvae. A mere absence of $P$. orientalis in CDC light traps set in forest habitats of Paloich area (Sudan) could not have been exclusively due to the failure of $P$. orientalis not being attracted to light as already described [7]. The absence of cracking type black soil or other breeding sites of $P$. orientalis were decisive. Dense forests could be devoid of soil cracks as already reported [8] and unsuitable for $P$. orientalis breeding. Habitats of $P$. orientalis were reported to have persistently lower normalized difference vegetation index (NDVI) value during the dry season and experienced more extreme dry and wet seasons than $P$. orientalis negative sites [15]. Our field observations in northwest Ethiopia concur with this. Typically, agricultural fields and thickets of $A$. seyal (sparse or thin), where $P$. orientalis was caught in abundance appeared to experience full exposure of sun during dry season whereas being covered with vegetation during rainy season. Agricultural fields and sparse or thin thickets of $A$. seyal, including A. seyal - B. aegyptiaca woodlands, could be a target for future control of kala-azar in the northwest Ethiopia and Sudan.

\section{Conclusion}

Less dense thickets of $A$. seyal and agricultural fields in Kafta Humera lowlands, which are characterized by deep black cracking soil in dry season, are breeding and resting habitats for $P$. orientalis, compared to dense mixed forests where $P$. orientalis shelters temporarily during rainy season. Kala-azar infections in Kafta Humera lowlands might have been related with the visits or permanent settlement on the agricultural fields where tickets of $A$ seyal often found in narrow depressions around the agricultural fields.

\section{Recommendations}

Further studies on man $-P$. orientalis contact and parasite isolations from the vectors, human and reservoir hosts in extra-domestic habitats will show the exact areas where labour migrants are exposed to infection of kala-azar.

\section{Competing interests}

The authors declare that they have no competing interests.

\section{Authors' contributions}

$W L, H T, M B, T G, A W$ and $A H$ designed the research and prepared the proposal. WL did sand fly collection, processing, data analysis and preparation of this manuscript. MB, HT, TG, AW and AH supervised the overall activities. AH critically reviewed the manuscript and $\mathrm{WL}$ and $\mathrm{AH}$ are the guarantors of the manuscript. All authors read and approved the final manuscript 


\section{Acknowledgment}

We would like to thank the Bill and Melinda Gates Foundation Global Health Program [Grant number OPPGH5336] and University of Gondar for funding this research. We would also thank Abel Haile, for technical assistance and sand fly collection, and Shewangizaw Sime (driver) and all the staffs in Humera who assisted us during our field and laboratory activities in Kafta Humera low lands. Our thanks also go to Tigray regional state and western Tigray Zone administration for their unreserved co-operation during the execution of this research.

\section{Author details}

'Department of Parasitology, School of Biomedical and Laboratory Sciences, College of Medicine and Health Sciences, University of Gondar, P.O. box: 196, Gondar, Ethiopia. ${ }^{2}$ Department of Zoology, Faculty of Life Science, Addis Ababa University, Addis Ababa, Ethiopia. ${ }^{3}$ Aklilu Lemma Institute of Pathobiology, Addis Ababa University, Addis Ababa, Ethiopia. ${ }^{4}$ Department of Microbiology \& Molecular Genetics, The Institute for Medical Research Israel-Canada, The Kuvin Centre for the Study of Infectious \& Tropical Diseases, The Hebrew University - Hadassah Medical School, The Hebrew University of Jerusalem, Jerusalem 91120, Israel. ${ }^{5}$ Department of Microbiology, Immunology \& Parasitology, Faculty of Medicine, Addis Ababa University, Addis Ababa, Ethiopia.

Received: 17 June 2014 Accepted: 18 July 2014

Published: 6 August 2014

\section{References}

1. Hailu A, Gebre-Michael T, Berhe N, Balkew M: From Leishmaniasis. In Epidemiology and Ecology of Health and Disease in Ethiopia. Volume 2. 2nd edition. Edited by Berhane Y, Hailemariam D, Kloos H. Addis Ababa: Shama Books; 2006:615-634

2. Chappuis F, Sundar S, Hailu A, Ghalib H, Rijal S, Peeling RW, Alvar J, Boelaert M: Visceral leishmaniasis: what are the needs for diagnosis, treatment and control? Nat Rev Microbiol 2007, 5(Suppl 7):873-882.

3. Killick-Kendrick R: The biology and control of phlebotomine sandflies. Clin Dermatol 1999, 17:279-289.

4. Gebre-Michael T, Malone JB, Balkew M, Ali A, Berhe N, Hailu A, Herzi AA: Mapping the potential distribution of Phlebotomus martini and $P$. orientalis (Diptera: Psychodidae), vectors of kala-azar in East Africa by use of geographic information systems. Acta Trop 2004, 90:73-86.

5. Gebre-Michael T, Lane RP: The roles of Phlebotomus martini and P. celiae (Diptera: Phlebotominae) as vectors of visceral leishmaniasis in the Aba Roba focus, southern Ethiopia. Med Vet Entomol 1996, 10:53-62.

6. Kirk R, Lewis DJ: Studies in leishmaniasis in the Anglo-EgyptianSudan. XI. Phlebotomus in relation to leishmaniasis in the Sudan. Trans $R$ Soc Trop Med Hyg 1955, 49:229-240

7. Quate LW: Leishmaniasis in the Sudan Republic: Phlebotomus sandflies of the Paloich area in the Sudan (Diptera: Psychodidae). J Med Entomol 1964, 1:213-268.

8. Hoogstraal H, Heyneman D: Leishmaniasis in the Sudan Republic. 30. Final epidemiological report. Am J Trop Med Hyg 1969, 18:1091-1210.

9. Gemetchu T, Zerihune A, Assefa G, Lemma A: Observations on the sandfly (Phlebotomidae) fauna of Setit-Humera (Northwestern Ethiopia). Ethiop Med J 1975, 13:41-51.

10. Fuller GK, Lemma A, Haile T, Gemeda N: Kala-azar in Ethiopia: survey of south-west Ethiopia. The leishmanin skin test and epidemiological studies. Ann trop Med Parasit 1979, 73:417-431.

11. Zeese W, Frank W: Present epidemiological situation of kala-azar in the Republic of Sudan. Zentra Bakteriol Hyg 1987, 264:414-421.

12. Ashford RW, Thomson MC: Visceral leishmaniasis in Sudan. A delayed development disaster? Ann Trop Med Parasitol 1991, 8:571-572.

13. Schorscher J, Goris M: Incrimination of Phlebotomus (Larroussius) orientalis as a vector of visceral leishmania sis in Western Upper Nile province, southern Sudan. Trans Roy Soc Trop Med Hyg 1992, 86:622-623.

14. Elnaiem DA, Hassan HK, Ward RD: Phlebotomine sandflies in a focus of visceral leishmaniasis in a border area of eastern Sudan. Ann Trop Med Parasitol 1997, 91:307-318.

15. Elnaiem A, Conners S, Thmoson M, Hassan M, Hassan H, Aboud A, Ashford W: Environmental determinants of the distribution of Phlebotomus orientalis in Sudan. Ann Trop Med Parasite 1998, 92:877-887.
16. Elnaiem DA, Hassan HK, Ward RD: Associations of Phlebotomus orientalis and other sandflies with vegetation types in the eastern Sudan focus of kala-azar. Med Vet Entomol 1999, 13:198-203.

17. Thomson MC, Elnaiem DA, Ashford RW, Connor SJ: Towards a kala-azar risk map for Sudan: mapping the potential distribution of Phlebotomus orientalis using digital data of environmental variables. Trop Med Int Health 1999, 4:105-113.

18. Widaa SO, Ahmed KA, Elsheikh Bari AA, Ali MM, Ibrahim MA, Bashir MA Mastour AA, Yagi ZA, Hassan MM: Sandflies (Diptera: Psychodidae) in a focus of visceral leishmaniasis in White Nile, Sudan. Mem Inst Oswaldo Cruz 2012, 107(4):470-475.

19. Ritmeijer K, Dejenie A, Assefa Y, Hundie B, Mesure J: A comparison of miltefosine and sodium stibogluconate for treatment of visceral leishmaniasis in an Ethiopian population with high prevalence of HIV infection. Clin Infect Dis 2006, 43:357-364.

20. WHO Expert Committee: Studies on Leishmaniasis vectors/Reservoirs and their control. The Old World, Tropical Africa. Geneva: World Health organization Technical Report Series; 1981:1-164

21. Haile T, Anderson SD: Visceral Leishmaniasis in Northern Ethiopia. E Afr Med J 2006, 83:389-392.

22. Argaw D, Mulugeta A, Herrero M, Nombela N, Teklu T, Tefera T, Belew Z, Alvar J, Bern C: Risk factors for visceral leishmaniasis among residents and migrants in Kafta-Humera, Ethiopia. PLoS Neg/ Trop Dis 7(11):e2543. www.plosntds.org 1 November 2013.

23. Tigray Region report: Livelihood Profile Tigray Region, Ethiopia. Humera Sesame and Sorghum Livelihood Zone. Tigray Regional report. Mekele, Ethiopia: 2007:1-13.

24. Abonnenc E, Minter DM: Bilingual keys for the identification of the sandflies of the Ethiopian region. Entomologie Medicale 1965, Cahiers No. 5: ORSTOM.

25. Lewis JA: A taxonomic review of the genus Phlebotomus (Diptera:Psychodidae). Bull Brit Mus (NH) (Ent) 1982, 45:121-209.

26. Gemetchu T: The distribution of sandflies (Diptera, Psychodidae, Phlebotominae) in northwest Ethiopia. Sinet: Ethiop J Sci 1983, 6:65-73.

27. Ashford RW, Hutchinson MP, Bray RS: Kala-azar in Ethiopia: epidemiological studies in a highland valley. Ethiop Med J 1973, 11:259-264.

doi:10.1186/1756-3305-7-359

Cite this article as: Lemma et al:: Population dynamics and habitat preferences of Phlebotomus orientalis in extra-domestic habitats of Kafta Humera lowlands - kala azar endemic areas in Northwest Ethiopia. Parasites \& Vectors 2014 7:359.

\section{Submit your next manuscript to BioMed Central and take full advantage of:}

- Convenient online submission

- Thorough peer review

- No space constraints or color figure charges

- Immediate publication on acceptance

- Inclusion in PubMed, CAS, Scopus and Google Scholar

- Research which is freely available for redistribution 